\title{
An Intercomparison of ERS-Scat and AMSR- E Soil Moisture Observations with Model Simulations over France
}

\author{
Christoph Rüdiger ${ }^{1, *}$ \\ Jean-Christophe Calvet ${ }^{1}$ \\ Claire Gruhier ${ }^{2}$ \\ Thomas Holmes ${ }^{3}$ \\ Richard de $\mathrm{Jeu}^{3}$ \\ Wolfgang Wagner ${ }^{4}$
}

\begin{abstract}
${ }^{1}$ CNRM-GAME, Météo-France/CNRS, France
${ }^{2}$ CESBIO, UMR5126 CNES/CNRS/IRD/UPS, France

${ }^{3}$ Faculty of Earth and Life Sciences, Vrije Universiteit Amsterdam, Netherlands

${ }^{4}$ Institute of Photogrammetry and Remote Sensing, Vienna University of Technology, Austria

* now at: Department of Civil and Environmental Engineering, The University of Melbourne, Australia
\end{abstract}

Submitted to:

Journal of Hydrometeorology

Date of first submission

19 November 2007

\author{
CORRESPONDING AUTHOR: \\ Jean-Christophe Calvet \\ Météo-France \\ CNRM/GMME/MC2 \\ Toulouse, France \\ Phone: +33 561079341 \\ Fax: +33 561079626 \\ Email: \\ calvet@meteo.fr
}




\section{Abstract}

This paper presents a study undertaken in preparation of the work leading up to the assimilation of SMOS observations into the land surface model (LSM) ISBA at Météo France. This study consists of an inter-comparison experiment of different space-borne platforms providing surface soil moisture information (AMSR-E and ERS-Scat) with the reanalysis soil moisture predictions over France from the model suite SIM (SAFRAN-ISBAMODCOU) of Météo France for the years 2003 to 2005. Both modelled and remotely sensed data are initially validated against in-situ observations obtained at the experimental soil moisture monitoring site SMOSREX in south-western France. Two different AMSR-E soil moisture products are compared in the course of this study (the official AMSR-E product from the National Snow and Ice Data Centre (NSIDC) and a new product developed at the Vrije Universiteit Amsterdam and NASA (VUA-NASA)), which were obtained using two different retrieval algorithms. This allows an additional assessment of the different algorithms, while using identical brightness temperature data sets. This study shows that a good correlation exists between AMSR-E (VUA-NASA), ERS-Scat, and SIM, generally for low altitudes and low-to-moderate vegetation covers ( 1.5 to $3 \mathrm{~kg} \mathrm{~m}^{2}$ vegetation water content), with a reduction in the correlation in mountainous regions. It is also shown that the AMSR-E (NSIDC) soil moisture product has significant differences, when compared to the other data sets. 
Soil moisture is the governing variable for modelling soil surface-to-atmosphere energy exchanges and land surface model (LSM) initialisation, as it controls both evaporation and transpiration from bare soil surfaces and vegetation covers. Consequently, a significant amount of studies have been and are currently being conducted to obtain soil moisture estimates through land surface modelling (e.g. Dirmeyer et al. 1999; Georgakakos and Carpenter 2006) and remotely sensed surface soil moisture observations (e.g. Wagner et al. 1999ab; Kerr et al. 2001; Njoku et al. 2003).

30 For the purpose of soil moisture remote sensing, observations in the microwave bands have been found to produce the best results. The optimal wavelength lies within the L-band range $(\sim 1-2 \mathrm{GHz})$, as interference through vegetation water content at this frequency range is

33 lower than at higher frequencies.. However, instruments have in the past been and are 34 currently operated at higher frequencies (above $5 \mathrm{GHz}$ ), mainly because none of these missions were dedicated soil moisture missions. The first such dedicated soil moisture 36 mission will be the Soil Moisture and Ocean Salinity mission (SMOS), to be launched in 37 2009. The first microwave instrument operated for an extensive time and within adequate wavelengths was the Scanning Multichannel Microwave Radiometer (SMMR) on Nimbus-7 (operational from 1978 to 1987), which operated at bands at and above 6.6GHz. SMMR was

40 followed by the Special Sensor Microwave/Imager (SSM/I; since 1987) and the similar

41 Tropical Rainfall Measuring Mission (TRMM) Microwave Imager (TMI; since 1997), which

42 operate at frequencies above $10 \mathrm{GHz}$. Instruments which are currently operational at

43 frequencies similar to SMMR (and therefore closer to L-band), are the Advanced Microwave

44 Scanning Radiometer for the Earth Observing System (AMSR-E) on board NASA's Aqua

45 satellite, WindSat on board the American Navy's Coriolis satellite, and the scatterometers on

46 board the European Remote Sensing satellites (ERS-1 \& -2). Finally, a new scatterometer 
47 (ASCAT) was launched on board ESA's MetOp satellite in 2006 and its data will soon be available operationally (Bartalis et al. 2007).

Despite almost 30 years of experience with these microwave remote sensing instruments, it is still necessary to validate the soil moisture products obtained from these instruments through in-situ soil moisture observations. However, such ground-truthing has only been achieved over small temporal and spatial scales (eg. the Soil Moisture Experiments (SMEX) or the Campaign for validating the Operation of SMOS (CoSMOS)), as it is economically and practically infeasible to observe soil moisture at high spatial and temporal resolution over large scales using in-situ observations, mainly because of its high spatial variability. Only in the present decade there have been attempts to establish long-term and large scale soil moisture observation networks or data banks such as the Global Soil Moisture Data Bank (Robock et al. 2000), the Goulburn River experimental catchment in Australia (Rüdiger et al. 2007), or SMOSMANIA in south-western France (Calvet et al. 2005). However, these data sets only represent single points in space. This lack of spatial extent limits the usefulness of such data sets for assimilation into large scale land surface models and also for disaggregation studies, as the large scale, but also subpixel variability is not captured with single point measurements. Moreover, satellite products are generally available at scales of about $0.25^{\circ}$ or $25 \mathrm{~km}$, which leads to problems in their validation process, due to the different spatial scales (spatially averaged satellite products are compared to point measurements). Consequently, new validation methods complementing the existing soil moisture networks have to be conceived (Wagner et al. 2007). Under the assumption that LSMs, forced with high quality atmospheric forcing data, adequately represent the surface soil moisture dynamics, the scale issues can be reduced. This assumption in turn will then allow the large-scale and long-term evaluation of the satellite products in terms of their temporal dynamics, as the products considered are essentially independent models. 
In this paper, both the need for large scale ground-truthing and understanding of the subpixel heterogeneity of soil moisture are addressed. First, the temporal correlation of satellite products at a large scale with a synthetic high-resolution surface soil moisture data base is presented. The high-resolution meteorological observation network throughout France (more than 1000 surface meteorological stations and more than 3500 daily rain gauges) has resulted in a high-quality atmospheric forcing data base (Quintana-Seguí et al. 2008) for the operational land surface model ISBA of Météo-France, within the modelling system SIM (SAFRAN-ISBA-MODCOU; Habets et al., 2008). The SIM model simulates the soil moisture dynamics.

The satellite products used for this study were obtained from AMSR-E and ERS-2. Furthermore, the recent development of a new retrieval algorithm for AMSR-E (Owe et al. 2007) allowed to compare the official AMSR-E product (Njoku et al. 2003) with this new data base. In the first part of this study, the different data sets used are discussed, followed by a brief comparison of those remotely sensed data sets and SIM with in-situ observations of the SMOSREX experimental site near Toulouse, France (de Rosnay et al. 2006), to determine their capability to represent the temporal soil moisture dynamics of a point or pixel. The good results of this analysis between the land surface model, in-situ observations, and satellite data also shows that previous results obtained over Spain (Wagner et al. 2007; one single satellite pixel), or over Australia (Draper et al. 2007; several in-situ observations for a number of pixels) can be extrapolated to a national or even continental scale, as they show the same tendencies. The differences between the various soil type data bases used in the satellite retrieval schemes and the model data base, make it difficult to compare absolute values. Consequently, the discussion of this paper will focus on the normalised data sets. In the second part, the inter-comparison study then presents the correlations and mean differences between all data sets (ie. also between the different satellite products). 


\section{Data Sets} mainland France. Nevertheless, the surface and climatic conditions throughout the country are sufficiently variable (ranging from sub-humid to alpine), to give a statistically sound data basis for a representative analysis. The years 2003-2005 were chosen for this study, as data exists for all sources (SIM - 1970 to 2006; ERS-Scat - 1992 to 2006; AMSR-E - 2003 to date; and SMOSREX - 2001 to date). Moreover, this 3-year period includes both very dry and very wet climatic conditions, which are necessary to determine the dynamic range of the soil moisture observations within each pixel. The following sections briefly outline the various data sets, used for this study.

The modelled surface soil moisture data base was obtained from the modelling system SAFRAN-ISBA-MODCOU (SAFRAN - atmospheric forcing data base; ISBA - land surface

112 model; MODCOU - hydrological routing model). Of these three model chain segments, only

113 SAFRAN and ISBA were of importance for the present study.

114 SAFRAN (Système d'analyse fournissant des renseignements atmosphériques pour la 115 nivologie) is a reanalysis forcing data base, initially developed to improve snowfall and

116 avalanche forecasting. Within SAFRAN, the main atmospheric forcing parameters are

117 analysed. Each atmospheric parameter is analysed individually using an optimal interpolation

118 method. The final size of a grid cell within SAFRAN is $8 \times 8 \mathrm{~km}^{2}$. For precipitation, however, 119 the actual pixel sizes of SAFRAN vary, as they represent zones of climatic conditions rather 120 than regularly gridded areas. Each climatic zone covers about $1000 \mathrm{~km}^{2}$, resulting in about 600 
121 such pixels over France. The forcing parameters are in principle assumed to be homogeneous

122 within one such pixel, however, they vary on a sub-pixel scale with topography. Apart from

123 precipitation the SAFRAN forcing data is available at 6-hourly intervals. Precipitation is

124 obtained using daily observations at the rain gauges and then interpolated into hourly time

125 steps as a function of the relative humidity during the day. The SAFRAN data base has

126 recently been validated against in-situ observations and found to be well correlated (Quintana-

127 Seguí et al. 2008).

128 The land surface model used in SIM is ISBA (Interactions of the Soil, Biosphere and

129 Atmosphere; Noilhan and Planton 1989; Mahfouf and Noilhan 1996), which is used

130 operationally as the land surface scheme within the numerical weather prediction system at

131 Météo-France. The soil layer and soil moisture dynamics are modelled within a 3-soil-layer

132 model (Boone et al. 1999), which is based on the force-restore approach, where the three soil

133 layers are a surface layer of $1 \mathrm{~cm}$ depth, forming part of a root zone layer above the third, deep

134 layer.

135 There is no previous study presenting a verification of the SIM surface soil moisture

136 product. On the other hand, the ISBA model has been extensively validated for various

137 biomes. In particular, a number of studies exist comparing a point-specific calibrated ISBA

138 version to actual in-situ soil moisture observations in France (Calvet et al. 1998a,b, Boone et

139 al. 1999, Calvet and Noilhan 2000, and Sabater et al. 2007). The latter case corresponds to

140 SMOSREX, and the former to a previous experiment (MUREX) in the same region. The

141 RMSE for those cases is, respectively, 0.06 and $0.07 \mathrm{~m}^{3} \mathrm{~m}^{-3}$, with a mean difference in the

142 order of 0.01 and $0.03 \mathrm{~m}^{3} \mathrm{~m}^{-3}$. In both cases the Nash efficiency was calculated with $0.65 / 0.59$.

143 Based on the results of Prigent et al. (2005), this level of error between in-situ observations

144 and model predictions is expected, while maintaining a good correlation despite the different

145 observation and model layer depths. The land surface parameters for ISBA are obtained from 
146 ECOCLIMAP (Masson et al. 2003). The parameters provided by ECOCLIMAP are originally

147 provided at $1 \mathrm{~km}$ resolution and are aggregated to the model resolution of $8 \mathrm{~km}$.

b. AMSR-E

AMSR-E is a passive microwave scanning radiometer, operating at six wavelengths

151 within the microwave spectrum $(6.925,10.65,18.7,23.8,36.5$, and $89 \mathrm{GHz})$ in horizontal and

152 vertical polarisations, flown on NASA's Aqua satellite. The total swath width during an

153 overpass is approximately $1445 \mathrm{~km}$, with footprint resolutions ranging from $56 \mathrm{~km}(6.925 \mathrm{GHz})$

154 to $5 \mathrm{~km}(89 \mathrm{GHz})$. Aqua is a sun-synchronous satellite orbiting Earth approximately 14 times

155 each day, with morning/descending and afternoon/ascending overpasses, at around

$1561.30 \mathrm{am} / \mathrm{pm}$. This configuration results in a repeat coverage of approximately every three days

157 in the equatorial latitudes and more frequent coverage in higher latitudes. For the particular

158 case of France, Aqua overpasses take place at 4 out of 5 days for both ascending and

159 descending orbits.

160 Currently, two different data products are freely available. The official product can be

161 obtained through the National Snow and Ice Data Center (NSIDC, hereafter AMSR-E

162 (NSIDC)), while a new product has recently been made available through the Vrije

163 Universiteit Amsterdam in collaboration with NASA (hereafter AMSR-E (VUA-NASA)).

164 Both products are briefly described in the following sections.

165 i. $\quad \underline{\text { AMSR-E (NSIDC) }}$

166 The AMSR-E (NSIDC) data used for this study were obtained from the operational Level

1673 B03 AMSR-E data set (Njoku 2006). While the original resolution at $10.65 \mathrm{GHz}$ is $\sim 38 \mathrm{~km}$,

168 the data is binned into regular $0.25^{\circ} \times 0.25^{\circ}$ pixels, through oversampling at $10 \mathrm{~km}$ intervals. 
The NSIDC method uses two low frequency dual polarized channels to optimize the three 170 parameters (soil moisture, vegetation optical depth and the effective soil temperature)

171 simultaneously. Originally, the method was developed and tested for the C- and X-band

172 channels. Unfortunately, severe radio-frequency interference (RFI) was discovered within C-

173 band $(6.925 \mathrm{GHz})$ over the USA and Japan and X-band over Italy and Great Britain (Li et al

$1742004,2006)$. For this reason, the retrieval algorithm was applied to the X-band (10.65GHz)

175 and $\mathrm{Ku}$-band $(18.7 \mathrm{GHz})$ brightness temperatures. This has some important disadvantages: 1)

176 the $18 \mathrm{GHz}$ channel introduces atmospheric influences and, 2) the observation depth of the

177 soil moisture product is reduced to $5-10 \mathrm{~mm}$, which is approximately half the potential range

178 of C-band and 3) vegetation attenuation effects are more significant than at lower frequencies.

ii. $\quad$ AMSR-E (VUA-NASA)

180 The VUA-NASA retrieval products from AMSR-E are derived according to the Land

181 Surface Parameter Model (LPRM) (Owe et al. 2007). The LPRM is a three-parameter

182 retrieval model for passive microwave data, using one dual polarized channel (either 6.925 or

$18310.65 \mathrm{GHz}$ ) for the retrieval of both surface soil moisture and vegetation water content

184 (VWC). The land surface temperature is derived separately from the vertically polarized

$185 \quad 36.5 \mathrm{GHz}$ channel.

186 The forward radiative transfer model in LPRM is based on one vegetation layer $(\tau-\omega$

187 approach) and the vegetation optical depth is parameterized as a function of the Microwave

188 Polarization Difference Index (MPDI) and soil moisture according to Meesters et al. (2005).

189 This method is applied globally, and requires no regional calibration or fitting parameters to

190 aid the retrieval process.

191 The main differences with the AMSR-E (NSIDC) soil moisture product lies in the use of

192 a higher frequency band for the retrieval of the land surface temperature (LST), and the 
193 parameterization of the vegetation optical depth, leaving only the soil moisture to be

194 optimized.

The ERS-Scat data is obtained through active microwave remote sensing, ie. an energy pulse is sent to the surface and the intensity of the returned signal is then used within the retrieval algorithm to derive a relative soil moisture state. ERS-Scat is operated at $5.3 \mathrm{GHz}(\mathrm{C}-$ band), observing only the vertically polarised backscatter within this band, thus resulting in a

201 similar observation depth as AMSR-E. RFI has been found to have little impact on active

202 microwave remote sensing at this frequency. ERS-Scat has a morning/descending and evening/ascending orbit at $10.30 \mathrm{am} / \mathrm{pm}$, with a varying repeat coverage of about 2 to 8 days.

204 The spatial resolution of an ERS-Scat footprint is in the order of 50km, while the soil moisture product is binned into pixels of $0.25^{\circ}$ (north-south extent) and $25 \mathrm{~km}$ (west-east extent). normalisation of the backscatter signal is done, using the minimum and maximum observed backscatter from the 1992-2000 period, as dry and wet references. The retrieval algorithm is described in detail in Wagner et al. (1999, 2003).

212 SMOSREX is an experimental field site for in-situ and remotely sensed soil moisture 213 observations jointly operated by various research institutes in France and located to the south 214 of Toulouse $\left(43^{\circ} 23^{\prime} \mathrm{N}, 1^{\circ} 17^{\prime} \mathrm{E}\right)$ in south-western France (De Rosnay et al. 2006). The overall 215 size of SMOSREX is approximately $6000 \mathrm{~m}^{2}$ separated into two areas with either bare soil or 216 fallow. The climate is temperate with monthly mean maximum temperatures of $5^{\circ} \mathrm{C}$ in winter 
217 and $24^{\circ} \mathrm{C}$ in summer and an average annual cumulative precipitation of about $650 \mathrm{~mm}$. The

218 surface soil consists of a sandy loam, with $16 \%$ clay, $47 \%$ silt, and $37 \%$ sand.

219 Most instruments installed at the site have been in operation since 2001. The main feature

220 of this site is a tower-mounted L-band radiometer for the production of multi-angle brightness

221 temperatures. Other instrumentation include a weather station, and soil temperature and

222 moisture sensors, installed at various points and depths. The soil moisture sensors (Theta

223 Probes (C) used for this study are located at four points within the fallow section of the site

224 (most representative for the overall region and therefore the model simulations), with a

225 spacing of only a few metres. The sensors are vertically inserted at the surface, therefore

226 integrating the soil moisture content from 0 to $6 \mathrm{~cm}$, and a temporally averaged soil moisture

227 content is stored every 30 minutes individually for all sensors. The calibration of the sensors

228 is presented in (De Rosnay et al. 2006).

229 For the purpose of this study, the in-situ observations were aggregated into daily averages

230 and compared to the respective data sets obtained through the model and remote sensing.

231 Spatially averaging the observations of those four probes reduces the effect of spatial

232 variability within and increases the representativity of the soil moisture observations, and also

233 reduces the individual observations to one point in space.

234

235

e. Data Preparation

236 The results presented in this paper are based solely on the data sets from descending

237 orbits (nighttime) to avoid overly solar effects in the satellite data, due to sun glint and strong

238 temperature gradients between the vegetation and the surface, and also within the surface

239 layer, but also due to Faraday rotation and temperature gradients within the sensor which are

240 more pronounced during daytime overpasses (Kerr and Njoku 1990). Other effects such as 
241 quick dry-down or the lack thereof due to local changes in solar radiation, which can not be

242 adequately represented in an LSM and in reality may be affected by cloud coverage and wind,

243 among other factors play a significant role in the daytime evolution of surface soil moisture.

244 While the in-situ observations were spatially and temporally averaged, the soil moisture

245 simulations were extracted for the time steps close to the overpass times of the satellites. A

246 comparison of the differences between the individual measurements of the soil moisture

247 probes and their spatial average at 6am and also between the daily average with the spatial

248 average at 6 am resulted in an RMSE of $0.036 \mathrm{~m}^{3} \mathrm{~m}^{-3}$ in both cases. This shows that spatial and

249 diurnal variabilities contribute to the same extent to the uncertainty in the in-situ observations.

250 The use of a spatially and temporally daily average is therefore justifiable.

251 All data have been reprojected from their original coordinate systems onto a regular

$2520.25^{\circ} \times 0.25^{\circ}$ grid using a nearest neighbour approach. As the overall footprints of AMSR-E

253 and ERS-Scat are in the order of $50 \mathrm{~km}$ with a spacing of about $10 \mathrm{~km}$ between the centre

254 points, and the gridded products used in this study are binned at $25 \mathrm{~km}$ or $0.25^{\circ}$, respectively, a

255 spatial shift in the data due to the reprojection process (a maximum of $12 \mathrm{~km}$ ) is not expected

256 to add any additional noise to the data or affect the data quality, as a footprint with its centre

$25712 \mathrm{~km}$ from the pixel centre would still include information from more than half of the land

258 surface corresponding to the pixel area due to its size. To obtain an average pixel value within

259 the reprojected pixels, all original pixels with their centre falling into one reprojected pixel

260 were averaged to one single value. This average value was then assumed to be the

261 representative soil moisture of the reprojected pixel. In the case of the satellite observations,

262 only one original pixel would generally fall into a reprojected pixel, due to the similarity in

263 size, so that no errors are introduced due to the averaging of two satellite pixels. For all data

264 sets, the same general rule applied for the reprojection process, to avoid inconsistencies

265 between the data sets introduced through the reprojection and aggregation process. 
In a brief study it was examined whether the variability between the soil moisture of high resolution SIM pixels with their averaged low resolution equivalent resulted in any errors within the analysis. However, no relationship between the this subpixel heterogeneity and the spatial distribution of the correlation coefficients between the different soil moisture products presented in the following section was found. approach presented by Pellarin et al. (2006), where the maximum and minimum of the soil moisture range was not determined by the soil type, but rather by the observed dynamic range within each individual pixel within the full study period (2003-2005). To exclude any abnormal outliers due to observational errors or instrument noise, the $90 \%$ confidence interval was chosen to define the upper and lower soil moisture content, respectively, using (1) and (2).

and

$$
\operatorname{int}^{-}(S M)=\mu(S M)-1.64 * \sigma(S M)
$$

where $i n t^{+}$and int $^{-}$are the upper and lower confidence limits; $\mu(S M)$ is the average soil moisture content for the pixel; and $\sigma(S M)$ the standard deviation of the soil moisture content

283 for each pixel. With the knowledge of the upper and lower soil moisture content the absolute 284 soil moisture value is then normalised using (3):

$285 \quad \theta_{n}=\frac{S M_{o b s}-i n t^{-}}{i n t^{+}-i n t^{-}}$

286 where $S M_{o b s}$ is the individual soil moisture observation and $\theta_{n}$ is its normalised soil moisture 287 value. As a simplification it is assumed that the data are normally distributed, so that $90 \%$ of 288 the data lie by definition within a range of $\mu \pm 1.64 \sigma$. All data outside of this range were 
discarded. Also, pixel values were excluded from the overall analysis, where SIM predicted

frozen soil water. As model simulations as such have no outliers due to instrumentation errors, no screening of extreme values is required. The soil moisture from SIM is therefore normalised using the modelled maxima and minima of each individual pixel, instead of $\mathrm{int}^{+}$ and int.

Pixels located over major urban agglomerations (ie. Lille, Paris, Lyon, Bordeaux, Toulouse, and Marseille) were not excluded. However, the correct representation of the soil moisture is doubtful, as SIM is not capable to give realistic soil moisture conditions over urban (and consequently sealed) areas, and moreover, the possibility of pixels subjected to potential radio-frequency interference (Li et al. 2004) is higher in these areas. Nevertheless, the number of these pixels is small $(<0.5 \%$ of the total), compared to the total over France and their overall effect on the statistical analyses was found to be negligible.

\section{Comparison of the soil moisture products with in-situ observations}

An evaluation of the surface soil moisture products obtained from SIM and the satellites was undertaken, using the same three years of in-situ soil moisture observations as for the remainder of this study (2003-2005). The in-situ data were obtained from the observations at the experimental site SMOSREX. The data from the four surface soil moisture sensors installed at SMOSREX, were averaged both spatially and over time, so that one daily averaged observation was obtained for each day. This approach reduced the existing noise levels in the in-situ observations, as discussed in the previous section. The model and satellite

310 data used here are the binned and reprojected data as for the large scale study in section 4 , as

311 described above. SIM was not especially calibrated to the conditions at SMOSREX. For this

312 evaluation study various statistical parameters were calculated: the root mean square error 
313 (RMSE), the mean difference or bias between two data sets, the correlation coefficient (r)

314 between two data sets, and the Nash efficiency coefficient $(\mathrm{N})$. All statistics presented in the

315 following sections were calculated for the normalised soil moisture values and are therefore

316 dimensionless.

317 In a first step, the absolute values of the soil moisture products were compared with the 318 in-situ data. For this purpose, the already normalised ERS-Scat data were transferred into

319 absolute values, using the known maximum and minimum surface soil moisture observations

320 at SMOSREX. While a good correlation exists between SIM and SMOSREX data sets, a

321 severe lack of soil moisture dynamics is observed for the AMSR-E (NSIDC) data set (not

322 shown). However, the AMSR-E (VUA-NASA) data is well correlated despite an apparent wet

323 bias. Finally, the ERS-Scat observations are also well correlated in terms of their temporal

324 dynamics. In contrast to the AMSR-E (VUA-NASA) data, the ERS-Scat data exhibits a dry

325 bias. Due to the different soil moisture dynamics and biases, it is difficult to compare the

326 various data sets in detail, consequently, all comparison in the remainder of this paper will be

327 undertaken with normalised data (Fig. 1).

328 The comparison of the normalised SIM and SMOSREX data sets shows a good temporal 329 correlation $(\mathrm{r}=0.755 ; \mathrm{N}=0.478)$, with a bias $(-0.083)$ towards the in-situ observations (ie. the

330 in-situ observations tend to be drier), with the exceptions of very dry conditions, when the

331 model has the tendency to overestimate the soil moisture at this site (Fig. 2). Throughout the

332 years, a higher level of surface soil moisture dynamics is observed within the model data (Fig.

333 1), which results in a root mean square error (RMSE) of 0.198. This phenomenon is explained

334 by inaccuracies in the forcing data due to the spatial interpolation process within SIM and the

335 differences in the thickness of the observed soil layers ( $1 \mathrm{~cm}$ for SIM against $0-6 \mathrm{~cm}$ for the

336 ThetaProbes). However, there are only few data points causing this noise and this is

337 consequently deemed acceptable. 
The normalised AMSR-E (NSIDC) data display a very high variation, with interchanging peaks and troughs every three months (Fig. 1). Every year, minimal values are reached during

340 winter and their maximum in summer. This recurring negative correlation with the in-situ data 341 results in a high $\mathrm{RMSE}$ and low overall correlation $(\mathrm{r}=0.132 ; \mathrm{N}=-0.734$; bias $=0.132$; $\mathrm{RMSE}$

$342=0.356$ ). In contrast to the comparison of the absolute data, the persistent wet bias in the

343 AMSR-E (VUA-NASA) data has been reduced due to the normalisation. Similar to the SIM

344 predictions, a strong correlation between in-situ and remotely sensed data is found in this case

345 with a wet bias towards the AMSR-E data $(\mathrm{r}=0.775 ; \mathrm{N}=0.471 ;$ bias $=0.072 ; \mathrm{RMSE}=0.194)$.

346 Finally, the ERS-Scat observations are also well correlated over time with the in-situ data $(\mathrm{r}=$

$3470.618 ; \mathrm{N}=0.125)$, however a dry bias $(-0.085)$ results in a more significant RMSE of 0.244

348 than for the AMSR-E (VUA-NASA) data. As ERS-Scat data are only available from August

3492003 onwards, the identical periods of data cover (ie. August 2003 - December 2005) for the

350 other surface soil moisture products was undertaken (not shown), in order to verify that the

351 first seven months did not introduce significant biases in the statistical analyses, which then 352 would not be seen in the ERS-Scat comparisons. The differences in correlation, RMSE, and 353 bias did not change significantly for any of the inter-comparisons covering either the full three 354 years or the period August 2003 - December 2005. Consequently, all comparisons shown in 355 the remainder of this paper are based on the full period. The Nash efficiency coefficient for 356 SIM and AMSR-E (VUA-NASA) are acceptable. They are also similar to each other 357 suggesting that the two data sets perform equally well compared to the in-situ observations,

358 while the low Nash efficiency of ERS-Scat is due to the relatively strong bias in the satellite 359 data. In the case of the AMSR-E (NSIDC) data, the negative Nash efficiency suggests by 360 definition that an average value of the in-situ observations would compare better with the 361 overall observations than the remotely sensed observations. This is an important finding as it 362 shows the extreme difference between the in-situ observations and the satellite product. 
Four aspects have to be considered for the cause of the differences observed in this

364 evaluation: i) the scale difference $\left(8 \mathrm{~km}\right.$ and $0.25^{\circ}$ for the model and the satellite, respectively,

365 against a single point observation), as the comparison or validation of soil moisture products

366 at different spatial scales will remain difficult in most cases, unless a representative catchment

367 average soil moisture monitoring site (Grayson and Western 1998) can be identified; ii) the

368 soil data base, as the model soil information constitutes an average of the soil particle size

369 distribution within an $8 \mathrm{~km} / 0.25^{\circ}$ pixel, which may result in significant differences compared

370 to the soil conditions at the point of observation (the particle size analysis for SMOSREX

371 yielded $16 \%$ clay, $47 \%$ silt, and $37 \%$ sand; the particle size distribution within ECOCLIMAP

372 is $25 \% / 25 \% / 50 \%$ ), iii) the forcing data, as it is obtained by interpolation between observations

373 and atmospheric predictions, which may miss localised events, iv) the observation depth, with

374 the model layer of $1 \mathrm{~cm}$ and approximately the same depth for the satellite observations

375 against the integrated soil moisture content at $0-6 \mathrm{~cm}$ for the in-situ observations, may result in

376 different dynamics.

377 Considering the above four aspects, SIM, AMSR-E (VUA-NASA) and ERS-Scat perform

378 well when compared to the SMOSREX in-situ observations, and also show a good

379 representation of the dynamic behaviour of the soil moisture content. For SIM, an RMSE of

3800.198 with a dynamic range of the surface soil moisture at the site of $\sim 0.3 \mathrm{~m}^{3} \mathrm{~m}^{-3}$, can be

381 translated into an absolute error in the soil moisture of just under $0.06 \mathrm{~m}^{3} \mathrm{~m}^{-3}$. This result is

382 particularly good, as SIM was not calibrated to the conditions at SMOSREX, but rather used

383 the vegetation and soil conditions obtained from ECOCLIMAP. Moreover, despite the

384 differences in scale these errors are identical to the performance of the site-specific calibrated

385 model.

386 Depending on the application, the calculated error may be considered large or acceptable.

387 For atmospheric studies, it is more important to obtain a good representation of the temporal 
388 dynamics, while the absolute soil moisture state is less important. On the other hand, an error

389 of $0.06 \mathrm{~m}^{3} \mathrm{~m}^{-3}$ exceeds the validation goals of future satellite missions (Kerr et al, 2001). In

390 the first case, the evaluation of satellite data against any benchmark is necessary, shown by

391 the lack of temporal dynamics in the AMSR-E (NSIDC) data. In the second case, two factors

392 influencing the RMSE have to be considered to qualify the above value of $0.06 \mathrm{~m}^{3} \mathrm{~m}^{-3}$ : i) the

393 mean difference or bias between SIM and SMOSREX and ii) the spatial uncertainty of the in-

394 situ observation. Biases, in the case of the normalised data 0.084 (or $0.025 \mathrm{~m}^{3} \mathrm{~m}^{-3}$ ), may be

395 removed using various techniques (eg. Drusch et al., 2005), while the uncertainty in the

396 spatial averaging of the four in-situ observations is in the order of $0.036 \mathrm{~m}^{3} \mathrm{~m}^{-3}$. In particular

397 the removal of the bias would lead to a significant decrease of the RMSE. Consequently, it is

398 concluded that SIM may be used with reasonable confidence for a large scale model

399 intercomparison study, assuming that ECOCLIMAP provides similarly good information for

400 all other model pixels.

401 While the correlations derived from Fig. 1 are relatively large for SIM, AMSR-E (VUA-

402 NASA) and ERS-Scat, much of the captured variability is seasonal (dry in summer, wet in

403 winter). In order to assess the coherence with the in-situ observations and to avoid seasonal

404 effects, monthly anomalies are calculated. The difference to the mean is calculated for a

405 sliding window of five weeks, and the difference is scaled to the standard deviation. Table 1

406 shows seasonal scores, including the Kendall statistics and p-value. All the products are

407 significantly correlated to the in-situ observations, except for satellite products at specific

408 periods of the year. While SIM presents significant correlations throughout the year, all the

409 satellite products are not significantly correlated to in-situ observations at wintertime (DJF).

410 This may be explained by the sensitivity of the microwave signal (either active or passive) to

411 soil freezing and by the reduced dynamics of the surface soil moisture at wintertime. Both

412 VUA-NASA and NSIDC products present high correlations of the anomalies for the other 
413 seasons. On the other hand, ERS-Scat has significant correlations at springtime (MAM), only.

414 The lack of significance of ERS-Scat during the summer and autumn seasons (JJA and SON, 415 respectively), may be explained by the small number of observations over the SMOSREX site 416 (28 and 41, respectively), compared with AMSR-E (184 and 175, respectively, for the VUA417 NASA product).

423 4. Inter-Comparison (all Data Sets)

\section{a. General Correlation (all data)}

Fig. 3 shows correlation maps of the different remote sensing and modelled data sets for all surface conditions and all years. A good correlation exists between the three data sets AMSR-E (VUA-NASA), ERS-Scat, and SIM, in particular for regions of herbaceous vegetation over regions with little relief, with a range of the coefficient of correlation from 0.2 to 0.9 . Areas with denser vegetation, such as the forest of Les Landes in the South-West along the Atlantic coast show a lower level of correlation, which would have to be expected due to the masking effect on the microwave emissions of the soil moisture through vegetation.

432 Similarly, low correlations are found in regions with strong relief such as the Massif Central and the Alps. The good correlation of ERS-Scat with SIM in the Italian Alps should be

434 ignored, as only a few data points were available due to the overpass rate of ERS over the 435 region and the filtering of days with frozen soils or snow. Mountainous regions cause errors in 436 both the modelling of soil moisture and its retrieval from satellite observations. First, there 
exists a high level of uncertainty in the soil depth and its variability in those regions, which impacts on the predictions of the soil moisture dynamics in the SIM model. Secondly, relief interferes with the retrieval of low resolution remotely sensed soil moisture observations and may cause considerable levels of errors (Mätzler and Standley 2000). The AMSR-E (NSIDC)

441 product has virtually only low correlations with any of the other data sets, even producing 442 negative correlations overall (Table 2).

443 This analysis also shows that previous results obtained over Spain (Wagner et al. 2007; 444 one single satellite pixel), or over Australia (Draper et al. 2007; several in-situ observations 445 for a number of pixels) can be extrapolated to a national or even continental scale, as they 446 show the same tendencies. In particular, the lack of soil moisture dynamics within the AMSR447 E (NSIDC) data set are apparent and are shown in all studies.

448 The data used to derive the spatial plots of Fig. 3 are summarised in Table 2 as showing 449 the respective coefficient of correlation (r), root mean square error (RMSE) and bias between 450 the data sets. Compared to SIM, the ERS-Scat data set has the highest overall correlation ( $\mathrm{r}=$ 4510.728 ) and lowest RMSE (0.201), followed by AMSR-E (VUA-NASA) with an $r=0.491$ and 452 an RMSE of 0.297. As mentioned before, AMSR-E (NSIDC) has a negative correlation of 453 0.014 with an RMSE of 0.370. The RMSE presented here is the RMSE obtained from the 454 normalised results, ie. it represents the relative error of the soil moisture dynamical range. 455 Assuming an average dynamic range of $0.3 \mathrm{~m}^{3} \mathrm{~m}^{-3}$ and that SIM gives accurate in-situ 456 observations, this would translate into an average error of $0.056 \mathrm{~m}^{3} \mathrm{~m}^{-3}$ for ERS-Scat, which is 457 higher than the design accuracy of $\operatorname{SMOS}\left(0.04 \mathrm{~m}^{3} \mathrm{~m}^{-3}\right)$.

458 Like the bias between the SIM and SMOSREX data sets, the biases shown between SIM 459 and the three satellite products are all positive. This suggests that a consistent dry bias exists 460 within SIM. A first explanation for the bias between SIM and SMOSREX are the different 461 thickness of the observed soil layers ( $1 \mathrm{~cm}$ in the model against $0-6 \mathrm{~cm}$ in-situ), as the deeper 
462 profile of the in-situ observations is likely to maintain a higher soil moisture content, as it is

463 less affected by evaporation than the thin surface layer in the model. Furthermore, other

464 aspects such as erroneous soil type information, biased forcing data, and biases in the soil

465 moisture retrieval for the satellites may result in consistent biases.

A comparison of vegetation maps with the results of Fig. 3 suggested a connection between the accuracy of the remotely sensed soil moisture information and the land cover.

469 Therefore, the dominant land surface cover within each satellite-type pixel was determined, 470 using the information from ECOCLIMAP, in order to identify vegetation specific correlations 471 for each data product. For this purpose, the different vegetation types within each $0.25^{\circ}$ pixel were aggregated into three dominant cover types: i) cultivated soils, ii) grasslands, and iii) forests (Fig. 4). Relatively good correlations exist between SIM, ERS-Scat and AMSR-E (VUA-NASA) for the two herbaceous vegetation covers (Fig. 5a \& b). Like in the analysis of the overall data set, ERS-Scat and SIM have the highest correlation coefficient and lowest RMSE. Similarly, the pairs SIM/AMSR-E (VUA-NASA) and AMSR-E (VUA-NASA)/ERS-

477 Scat have slightly lower correlation coefficients and higher RMSEs, and AMSR-E (NSIDC) having negative correlations throughout. These results (with the exception of the AMSR-E (NSIDC) data) are not surprising given that remotely sensed soil moisture information should theoretically be retrievable with a high level of accuracy over herbaceous vegetation types. In herbaceous vegetation covers, active and passive methodologies are expected to show similar 482 performances, especially when using a similar frequency. The higher correlations of ERS483 Scat and SIM as compared to AMSR-E (VUA-NASA) and SIM, shows potential for improvement of the AMSR-E (VUA-NASA) product. Part of the difference might be 
487 the soil moisture content is limited to a maximum of $0.5 \mathrm{~m}^{3} \mathrm{~m}^{-3}$. However, it was found that

488 the surface soil moisture states often reached this point of saturation (Fig. 1). Consequently, if

489 this constraint were to be relaxed, and the retrieval process were allowed to produce higher

490 values, a quasi-normalised soil moisture product may be obtained (this aspect has been

491 considered for the next version of soil moisture data, which has recently been made

492 available). However, as a consequence of this constraint, the maximum soil moisture is

493 currently underestimated, which leads to an underestimation of the dynamic range, and

494 consequently a wet bias in the AMSR-E (VUA-NASA) data. The methodology behind the

495 ERS product avoids this caveat, by scaling between minimum and maximum observed signal

496 over the period 1992-2000.

497 The comparison of the various data sets for forested regions (Fig. 5c) overall shows lower 498 correlations and higher RMSEs. Again, ERS-Scat produces the best correlation with SIM, 499 followed by AMSR-E (VUA-NASA) and AMSR-E (NSIDC). Moreover, the ERS-Scat soil

500 moisture product appears to conserve its good correlation with SIM from the analysis of the

501 herbaceous vegetation types. Under the assumption that SIM is equally valid for forested

502 regions as for regions with low vegetation, it may be concluded that two effects may influence

503 the consistency of ERS-Scat for different vegetation types. Firstly, the retrieval process of

504 ERS-Scat implicitly takes into consideration the vegetation type by scaling the current signal

505 between the wet end dry ends of its long-term data base. This statement has significance for

506 other soil moisture missions in both active and passive microwave remote sensing, as the

507 approach taken for the retrieval of ERS-Scat soil moisture may be applied along with more

508 sophisticated radiative transfer models. Secondly, the ERS-Scat is well calibrated and has a

509 low radiometric noise of about $0.15 \mathrm{~dB}$, which allows estimating soil moisture even in areas

510 where abundant forest cover reduces the effective sensitivity of backscatter to soil moisture. 
511 An aspect of the data visible within the scatterplots of Fig. 5 is the apparent bi-modality

512 of the SIM data with data clouds forming for the lower and upper value ranges. Fig. 6 and 7

513 show histograms of the surface soil moisture from the four different low-resolution data

514 sources (SIM, AMSR-E (VUA-NASA), AMSR-E (NSIDC), and ERS-Scat) for SMOSREX

515 and for the whole of France, respectively. The histograms of the various data sources show

516 different patterns at the local scale (Fig. 6). While SIM and ERS-Scat show clear bi-

517 modalities, this is not the case for the two AMSR-E products, with AMSR-E (VUA-NASA)

518 having several peaks with a saturation at 1, and AMSR-E (NSIDC) data being almost

519 normally distributed, though all data sets, have a minima in the range of 0.4 to 0.6 . The

520 histogram of the in-situ data at SMOSREX (Fig. 6e) also shows a bi-modality, although with

521 its maximum in the wet spectrum. This would suggest that preferred soil moisture states exist

522 at SMOSREX, but that the distribution is not correctly captured by the various models.

523 The non-normal distribution of the histograms have significance for the normalisation

524 process, as it was previously assumed that the soil moisture distribution was sufficiently

525 normal at each point. A violation of the assumption of normality would mean that the $90 \%$

526 confidence interval could not be calculated with the equations (1) and (2). To assess this, the

527 distribution of the soil moisture states at the national scale was studied (Fig. 7).

528 An exception here is SIM with a clear peak in the dry spectrum (0.2) and AMSR-E

529 (VUA-NASA) being skewed towards the wet end (Fig. 7). The overall distributions show that

530 SIM retains its clear bi-modality with a peak in the dry spectrum, while the ERS-Scat and

531 AMSR-E data become more normally distributed. For the AMSR-E data sets, the distribution

532 of AMSR-E (NSIDC) data becomes almost Gaussian with a slight skew towards the wet end,

533 while the AMSR-E (VUA-NASA) data is more evenly distributed. As the normalisation

534 procedure of Pellarin et al. (2006) is only applied to the AMSR-E data, it is concluded that the

535 normalisation process is still applicable to the majority of the pixels throughout France. 
The results shown here are in line with other studies. For example, Teuling et al. (2005)

537 showed that preferred soil moisture states may exist locally. However, they found that this

538 effect could not be observed at all sites studied and that it could not be linked to local soil

539 conditions and may therefore be a random effect. This conclusion is supported by Fig. 6 and

5407 , where the histograms for the data at SMOSREX suggest that local preferred wet and dry

541 states exist, while the distribution of all observations over France is not bimodal.

c. Intra-seasonal Correlation

The bi-modality presented in the previous section is unlikely to be caused by differences

544 in the soil types, as the soil moisture data were normalised, and SMOSREX also appears to 545 have this distribution (Fig. 6e). The bi-modality is related to the varying soil moisture states,

546 which are caused by either precipitation events or seasons. As the effect of precipitation

547 events on the soil moisture distribution is difficult to obtain, the results obtained for the

548 cultivated soils in Fig. 5 were separated according to the various seasons. This analysis (Fig.

549 8) clearly shows the different preferred soil moisture states in summer (dry) and winter (wet),

550 which are consequently the main reason for the creation of the data clouds in Fig. 5. Similar

551 results of preferred soil moisture states during the various seasons has been shown by Settin et

552 al. (2007), where they were largely attributed to the precipitation intervals and intensities

553 during the various seasons. Interestingly, the two AMSR-E products have nearly the same

554 correlations with SIM during springtime, which would suggest that the two radiative transfer

555 models work similarly well during this period.

556

557

558 5. Conclusion 
In this paper, an intercomparison study of several remotely sensed surface soil moisture

560 products with the re-analysis LSM predictions over France has been presented. First, the LSM

561 predictions, and the satellite observations were compared with a 3-year in-situ surface soil

562 moisture data set from an experimental site in south-western France (SMOSREX) to

563 determine their capability to represent the temporal dynamics of a point or pixel. A good

564 correlation was found between the model predictions and the in-situ data, despite a slight dry

565 bias within the model predictions. Based on this evaluation, it was then assumed that the land

566 surface model predictions over France may be used as a credible approximate estimate in the

567 absence of more direct surface soil moisture observations for the whole country.

568 The analyses of this study, have shown that two of the three satellite data sets (AMSR-E

569 (VUA-NASA) and ERS-Scat) have generally a good correlation with the model predictions,

570 while the AMSR-E (NSIDC) data set did not correlate well with any of the other data sets.

571 Generally, the AMSR-E (NSIDC) data showed a significant lack of seasonal soil moisture

572 dynamics, which was well captured by the other data sets. These results suggest that the

573 AMSR-E (NSIDC) data set is not correct, as three other independent models (a physically

574 based radiative transfer model, an empiric soil moisture retrieval scheme, and a land surface

575 model) show a good correlation with each other. This is further supported by the good

576 correlation between SIM, AMSR-E (VUA-NASA), ERS-Scat and the in-situ observations at

577 SMOSREX. It is possible that those three models are all wrong and coincidentally produce

578 the same results, though the comparison with SMOSREX suggest that this is not likely. The

579 results of the observations obtained from the scatterometer additionally highlights the

580 potential use of active microwave data sets, which will be continued by the MetOp ASCAT

581 observations.

582 The analysis of de-trended time series (monthly anomalies) of surface soil moisture over

583 the SMOSREX site shows that short term variations of SIM and all the satellite products 
584 (included the NSIDC AMSR-E product) are meaningful. The significance is less for ERS-

585 Scat, which has a high sampling time.

586 For the moment it has to be acknowledged that there exists a good correlation between

587 some products for densely vegetated areas, but further studies are required to validate their

588 physical meaning or relevance. Given that the we present only the temporal dynamics in this

589 paper, it is interesting to learn that some satellite products appear to represent those dynamics

590 better than others, even for forested areas.

591 While in-situ observations averaged to the land surface model or remotely sensed pixel

592 scale may be better suited for the evaluation of both land surface or radiative transfer models,

593 these observations are still sparse and difficult to obtain. This study presents an alternative to

594 the use of in-situ observations for such large scale evaluations through the inter-comparison

595 of independent and apparently similar soil moisture estimates from different models.

597 Finally, the good correlations between point observations and the low resolution model

598 predictions and satellite observations also show the importance of single point observations

599 for the verification of LSM and remotely sensed soil moisture products. They also support the

600 need of the installation of new and the maintenance of existing soil moisture monitoring

601 networks. This is particularly true for forested and mountainous regions, which in the past

602 have been neglected when new soil moisture monitoring sites were established. With the need

603 for the evaluation of land surface model performances and satellite validation campaigns, the

604 relatively few existing networks are not sufficient.

605

606

607 Acknowledgments 
608 The authors acknowledge the NSIDC for the AMSR-E (NSIDC) data set. Eric Martin and

609 Jean-François Mahfouf from the CNRM are thanked for providing access to the SIM data

610 base and fruitful discussions. During the course of this study, Christoph Rüdiger was financed

611 through a post-doctoral fellowship with the Centre National d'Etudes Spatiales (CNES). The

612 SMOSREX project was co-funded by the «Programme National de Télédétection Spatiale»

613 and by the «Programme Terre Océan Surface Continentales et Atmosphère» (CNES), and by

614 participants to the experiment: CESBIO (CNES, CNRS, IRD, UPS), CNRM/GAME (Météo-

615 France, CNRS), INRA, and ONERA, all in the framework of the SMOS science preparatory

616 program.

617

618 
References

Boone, A., J.-C. Calvet, and J. Noilhan, 1999: Inclusion of a third soil layer in a land-surface scheme using the force-restore method, J. Appl. Meteorol., 38, 1611-1630.

Bartalis, Z., W. Wagner, V. Naeimi, S. Hasenauer, K. Scipal, H. Bonekamp, J. Figa, and C. Anderson, 2007: Initial soil moisture retrievals from the METOP-A Advanced Scatterometer (ASCAT). Geophys. Res. Lett., 34, L20401, 10.1029/2007GL031088

Bosch, D.D., V. Lakshmi, T.J. Jackson, M. Choi, and J.M. Jacobs, 2006: Large scale measurements of soil moisture for validation of remotely sensed data: Georgia soil moisture experiment of 2003. J. Hydrol., 323, 120-137.

Calvet, J.-C., J. Noilhan, and P. Bessemoulin, 1998a: Retrieving the root-zone soil moisture from surface soil moisture or temperature estimates: a feasibility study based on field measurements, J. Appl. Meteorol., 37, 371-386.

Calvet, J.-C., J. Noilhan, J.-L. Roujean, P. Bessemoulin, M. Cabelguenne, A. Olioso, and J.-P. Wigneron, 1998b: An interactive vegetation SVAT model tested against data from six contrasting sites, Agr. For. Meteorol., 92, 73-95.

Calvet, J.-C., P. Bessemoulin, J. Noilhan, C. Berne, I. Braud, et al., 1999: MUREX: a landsurface field experiment to study the annual cycle of the energy and water budgets, Ann. Geophys., 17, 838-854.

Calvet, J.-C., and J. Noilhan, 2000: From near-surface to root-zone soil moisture using yearround data, J. Hydrometeorol., 1, 393-411.

Calvet, J.-C., J. Muñoz Sabater, V. Vogt, J.-P. Wigneron, Y. Kerr, P. de Rosnay, C. Prigent, and T. Pellarin, 2005: Demonstration of the assimilation of the future SMOS data by using field and airborne campaigns. Abstracts volume, Geophys. Res. Abstr., 7, 04023, Sref-ID: 1607-7962/gra/EGU05-A-04023.

Cosh, M.H., T.J. Jackson, P. Starks, and G. Heathman, 2006: Temporal stability of surface soil moisture in the Little Washita River watershed and its applications in satellite soil moisture product validation. J. Hydrol., 323, 168-177.

De Rosnay, P., et al., 2006: SMOSREX: A long term field campaign experiment for soil moisture and land surface processes remote sensing. Remote Sens. Environ., 102, $377-$ 389, doi:10.1016/j.rse.2006.02.021.

Dirmeyer, P. A., A. J. Dolman, and N. Sato, 1999: The Global Soil Wetness Project: A pilot project for global land surface modeling and validation. Bull. Am. Meteorol. Soc., 80, 851-878.

Draper, C.S., J.P. Walker, P.J. Steinle, R.A.M. de Jeu, and T.R.H. Holmes, 2007: Remotely sensed soil moisture over Australia from AMSR-E. Proceedings, MODSIM 2007 International Congress on Modelling and Simulation, Christchurch, New Zealand, Modelling and Simulation Society of Australia and New Zealand, in press.

Georgakakos, K.P., and T.M. Carpenter, 2006: Potential value of operationally available and spatially distributed ensemble soil water estimates for agriculture. J. Hydrol., 328, 177-191.

Grayson, R.B., and A.W. Western, 1998: Towards areal estimation of soil water content from point measurements: time and space stability of mean response. J. Hydrol., 207, 68-82. 
Habets, F., A. Boone, J.L. Champeaux, P. Etchevers, L. Franchistéguy et al., 2008: The SAFRAN-ISBA-MODCOU hydrometeorological model applied over France. $J$. Geophys. Res., 113, D06113, doi:10.1029/2007JD008548.

Kerr, Y.H., P. Waldteufel, J.-P. Wigneron, J. Font, and M. Berger, 2001: Soil moisture retrieval from space: The Soil Moisture and Ocean Salinity (SMOS) mission. Geosci. Remote Sens., 39 (8), 1729-1735.

Li, L., E.G. Njoku, E. Im, P.S. Chang, and K. St. Germain, 2004: A preliminary survey of radio-frequency interference over the U.S. in Aqua AMSR-E data. Geosci. Remote Sens., 42 (2), 380-390.

Li, L., P.W. Gaiser, M.H. Bettenhausen, and W. Johnston, 2006: WindSat radio-frequency interference signature and its identification over land and ocean. Geosci. Remote Sens., 44 (3), 530-539.

Mätzler, C., and A. Standley, 2000: Relief effects for passive microwave remote sensing. Int. J. Remote Sensing, 21, 2403-2412.

Meesters, A.G.C.A., R.A.M. De Jeu, and M. Owe, 2005: Analytical derivation of the vegetation optical depth from the microwave polarization difference index, Geosc. Remot. Sens. Lett., 2(2),121-123.

National Snow and Ice Data Center (NSIDC). AMSR-E Level 3 B03 data set. http://nsidc.org/data/amsre/ (last accessed 7 November 2007).

Njoku, E.G., Jackson, T.J., Lakshmi, V., Chan, T.K., and S.V. Nghiem, 2003: Soil moisture retrieval from AMSR-E. Geosci. Remote Sens., 41 (2), 215-229.

Noilhan, J., and S. Planton, 1989: A simple parameterization of land surface processes for meteorological models. Mon. Wea. Rev., 117, 536-549.

Noilhan, J., and J.-F. Mahfouf, 1996: The ISBA land surface parameterization scheme, Global Planet. Change, 13, 145-159.

Owe, M., R. de Jeu, and J. Walker, 2001: A methodology for surface soil moisture and vegetation optical depth retrieval using the Microwave Polarisation Difference Index. Geosci. Remote Sens., 39 (8), 1643-1654.

Owe, M., R. de Jeu, and T. Holmes, 2007: Multi-Sensor Historical Climatology of SatelliteDerived Global Land Surface Moisture, J. Geophys. Res., doi:10.1029/2007JF000769, in press.

Pellarin, T., J.-C. Calvet, and W. Wagner, 2006: Evaluation of ERS scatterometer soil moisture products over a half-degree region in southwestern France. Geosc. Remot. Sens. Lett., 33, L17401, doi:10.1029/2006GL027231.

Prigent, C., F. Aires, W. B. Rossow, and A. Robock, 2005: Sensitivity of satellite microwave and infrared observations to soil moisture at a global scale: Relationship of satellite observations to in situ soil moisture measurements, J. Geophys. Res., 110, D07110, doi:10.1029/2004JD005087.

Quintana-Seguí, P., P. Le Moigne, Y. Durand, E. Martin, F. Habets, et al., 2008: Analysis of near-surface atmospheric variables: validation of the SAFRAN analysis over France. J. Appl. Meteorol. Climatol., 47, 92-107, doi:10.1175/2007JAMC1636.1.

Robock, A., K.Y. Vinnikov, G. Srinivasan, J.K. Entin, S.E. Hollinger, N.A. Speranskaya, S. Liu, and A. Namkhai, 2000: The global soil moisture data bank. Bull. Am. Meteorol. Soc., 81, 1281- 1299. 
Rüdiger, C. et al., 2007: Goulburn River experimental catchment data set. Water Resour. Res., 43, W10403, doi:10.1029/2006WR005837.

Sabater, J.M., L. Jarlan, J.-C. Calvet, F. Bouyssel, and P. De Rosnay, 2007: From near-surface to root-zone soil moisture using different assimilation techniques, J. Hydrometeorol., 8, 194-206.

Settin, T., G. Botter, I. Rodriguez-Iturbe, and A. Rinaldo, 2007: Numerical studies on soil moisture distributions in heterogeneous catchments. Water Resour. Res., 43, W05425, doi:10.1029/2006WR005737.

Teuling, A.J., R. Uijlenhoet, and P.A Troch, 2005: On bimodality in warm season soil moisture observations. Geophys. Res. Lett., 32, L13402, doi:10.1029/2005GL023223.

Vauchaud, G., A. Passerat de Silans, A. Balabanis, and M. Vauclin, 1985: Temporal stability of spatially measured soil water probability density function. Soil Sci. Soc. Am. J., 49, $822-828$

Wagner, W., G. Lemoine, M. Borgeaud, and H. Rott, 1999a: A study of vegetation cover effects on ERS scatterometer data. Geosci. Remote Sens., 37 (2), 938-948.

Wagner, W., J. Noll, M. Borgeaud, and H. Rott, 1999b: Monitoring soil moisture over the Canadian prairies with the ERS scatterometer. Geosci. Remote Sens., 37 (1), 206-216.

Wagner, W., V. Naeimi, K. Scipal, R. de Jeu, and J. Martínez-Fernández, 2007: Soil moisture from operational meteorological satellites. Hydrogeol. J., 15,121-131. 


\section{Figures}

\section{$\underline{\text { Figures }}$}

Figure 1. Time series plots (2003-2005) of the normalised values of the in-situ observations at SMOSREX (black lines) and the four surface soil moisture products, SIM, AMSR-E (NSIDC), AMSR-E (VUA), and ERS-Scat (+). The model predictions and satellite observations were obtained from respective low-resolution pixels covering SMOSREX.

Figure 2. Scatterplot of the normalised in-situ soil moisture observations at SMOSREX (vertical axis) with the four low-resolution data sets (SIM, AMSR-E (VUA), AMSR-E (NSIDC), and ERS-Scat) for the years 2003-2005. Darker regions show a higher density of data points.

Figure 3. Maps of the coefficient of correlation between the various soil moisture products (normalised values) over mainland France. The circles highlight the 6 major metropolitan areas of France.

Figure 4. Location of pixels with the different dominant land cover types (cultivated soils, grasslands, and forests), based on the fractional covers obtained from Ecoclimap and aggregated to $0.25^{\circ}$ resolution.

Figure 5. Vegetation type specific comparison of the different soil moisture products for the three dominant vegetation types (a) cultivated soils, b) grasslands, c) forests), using the data from the period 2003-2005. The scatterplots and their corresponding statistics are located on opposite sides of each figure, ie. the scatterplot of the data pair SIM-AMSR (VUA) is in the 
top left hand corner, while the respective statistical values are found in the bottom right hand corner. Darker regions show a higher density of data points.

Figure 6. Histograms showing the relative frequency (vertical axis) of the various normalised soil moisture observations (horizontal axis) and predictions for the years 2003-2005 for the SMOSREX site: SIM model, AMSR-E product of VUA-NASA, AMSR-E product of NSIDC, ERS-Scat product of University of Vienna, in situ observations.

Figure 7. Histograms showing the relative frequency (vertical axis) of the various normalised soil moisture observations (horizontal axis) and predictions for the years 2003-2005 for whole of France: SIM model, AMSR-E product of VUA-NASA, AMSR-E product of NSIDC, ERSScat product of University of Vienna.

Figure 8. Scatterplots showing the comparison of the various soil moisture products for pixels with herbaceous vegetation only (cultivated soils and grasslands) for the four seasons a) spring, b) summer, c) autumn, and d) winter. The scatterplots and their corresponding statistics are located on opposite sides of each figure, ie. the scatterplot of the data pair SIMAMSR (VUA) is in the top left hand corner, while the respective statistical values are found in the bottom right hand corner. Darker regions show a higher density of data points. 


\section{$\underline{\text { Tables }}$}

Table 1 - Comparison of monthly anomalies of surface soil moisture products (SIM, AMSRE, ERS-Scat) with in-situ 0-6cm observations at the SMOSREX site, for three pooled annual cycles (2003 to 2005).

\begin{tabular}{|l|c|c|c|c|c|c|c|}
\hline Product & Season & Number & Correlation & Bias & RMSE & $\begin{array}{c}\text { Kendall } \\
\tau\end{array}$ & $\begin{array}{c}\text { Kendall } \\
\text { p-value }\end{array}$ \\
\hline SIM & All & 794 & 0.61 & 0.01 & 0.79 & 0.63 & $* * * *$ \\
\hline SIM & DJF & 121 & 0.44 & -0.03 & 0.93 & 0.53 & $* *$ \\
\hline SIM & MAM & 219 & 0.74 & 0.01 & 0.65 & 0.73 & $* * * *$ \\
\hline SIM & JJA & 255 & 0.58 & 0.03 & 0.78 & 0.58 & $* * * *$ \\
\hline SIM & SON & 199 & 0.65 & 0.04 & 0.79 & 0.66 & $* * * *$ \\
\hline AMSR-E (NSIDC) & All & 698 & 0.46 & 0.01 & 0.88 & 0.39 & $* * * *$ \\
\hline AMSR-E (NSIDC) & DJF & 95 & 0.27 & -0.20 & 0.99 & 0.17 & NS \\
\hline AMSR-E (NSIDC) & MAM & 192 & 0.62 & 0.11 & 0.77 & 0.54 & $* * * *$ \\
\hline AMSR-E (NSIDC) & JJA & 219 & 0.23 & 0.02 & 1.03 & 0.21 & $* *$ \\
\hline AMSR-E (NSIDC) & SON & 192 & 0.54 & 0.01 & 0.88 & 0.48 & $* * * *$ \\
\hline AMSR-E (VUA-NASA) & All & 606 & 0.38 & 0.01 & 0.97 & 0.38 & $* * * *$ \\
\hline AMSR-E (VUA-NASA) & DJF & 75 & 0.12 & -0.07 & 1.05 & 0.01 & NS \\
\hline AMSR-E (VUA-NASA) & MAM & 172 & 0.49 & 0.09 & 0.90 & 0.53 & $* * * *$ \\
\hline AMSR-E (VUA-NASA) & JJA & 184 & 0.28 & 0.01 & 1.00 & 0.28 & $* * *$ \\
\hline AMSR-E (VUA-NASA) & SON & 175 & 0.42 & 0.00 & 1.01 & 0.44 & $* * * *$ \\
\hline ERS-Scat & All & 133 & 0.34 & -0.08 & 0.85 & 0.30 & $* *$ \\
\hline ERS-Scat & DJF & 32 & 0.57 & -0.12 & 0.51 & 0.39 & NS \\
\hline ERS-Scat & MAM & 32 & 0.55 & -0.06 & 0.54 & 0.57 & $*$ \\
\hline ERS-Scat & JJA & 28 & 0.28 & -0.10 & 0.64 & 0.30 & NS \\
\hline ERS-Scat & SON & 41 & 0.19 & 0.02 & 0.81 & 0.07 & NS \\
\hline
\end{tabular}

The monthly anomaly is the difference to the mean divided by the standard deviation, for a period of 5 weeks. The

Kendall $\tau$ is a non-parametric measure of correlation that assesses how well an arbitrary monotonic function could describe the relationship between two variables, without making any assumptions about the frequency distribution of the variables. It is used to measure the degree of correspondence between two rankings and assessing the significance of this correspondence. The p-value indicates the significance of the test, if it is small (below 0.05 at least), it means that the correlation is not a coincidence. The following thresholds on p-values are used: (i) NS (non significant) for p-value greater than 0.05 , (ii) * between 0.05 and 0.01 , (iii) ** between 0.01 and 0.001 , (iv) *** between 0.001 and 0.0001 and (v) $* * * *$ below a value of 0.0001 . 
Table 2 - Statistics of the inter-comparison between the difference data sets (normalised surface soil moisture data). The values in each cell correspond to the coefficient of correlation, bias, and RMSE, respectively.

\begin{tabular}{|l|c|c|c|c|}
\hline & & SIM & ERS-Scat & $\begin{array}{c}\text { AMSR-E } \\
\text { (VUA-NASA) }\end{array}$ \\
\hline AMSR-E & $\mathrm{r}$ & -0.014 & -0.099 & -0.115 \\
(NSIDC) & bias & 0.215 & 0.040 & 0.043 \\
& RMSE & 0.370 & 0.363 & 0.361 \\
\hline \multirow{2}{*}{ AMSR-E } & $\mathrm{r}$ & 0.491 & 0.397 & \\
(VUA-NASA) & bias & 0.177 & 0.099 & \\
\hline & RMSE & 0.297 & 0.296 & \\
ERS-Scat & $\mathrm{r}$ & 0.728 & & \\
& bias & 0.093 & & \\
& RMSE & 0.201 &
\end{tabular}




\section{Figures}

Fig. 1 Time series plots (2003-2005) of the normalised values of the in-situ observations at SMOSREX (black lines) and the four surface soil moisture products, SIM, AMSR-E (NSIDC), AMSR-E (VUA), and ERS-Scat (+). The model predictions and satellite observations were obtained from respective low-resolution pixels covering SMOSREX.
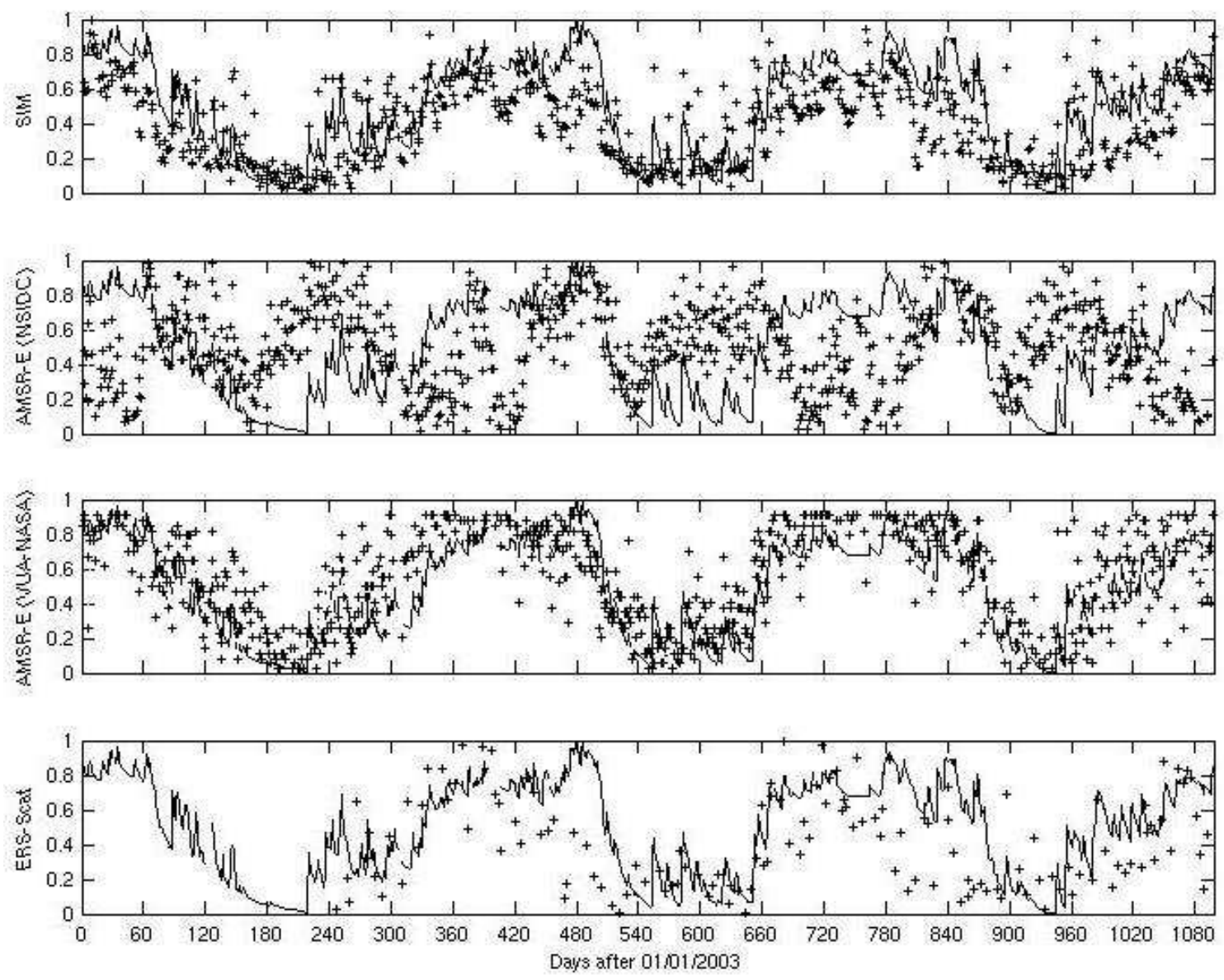
Fig. 2 Scatterplot of the normalised in-situ soil moisture observations at SMOSREX (vertical axis) with the four low-resolution data sets (SIM, AMSR-E (VUA), AMSR-E (NSIDC), and ERS-Scat) for the years 2003-2005. Darker regions show a higher density of data points.
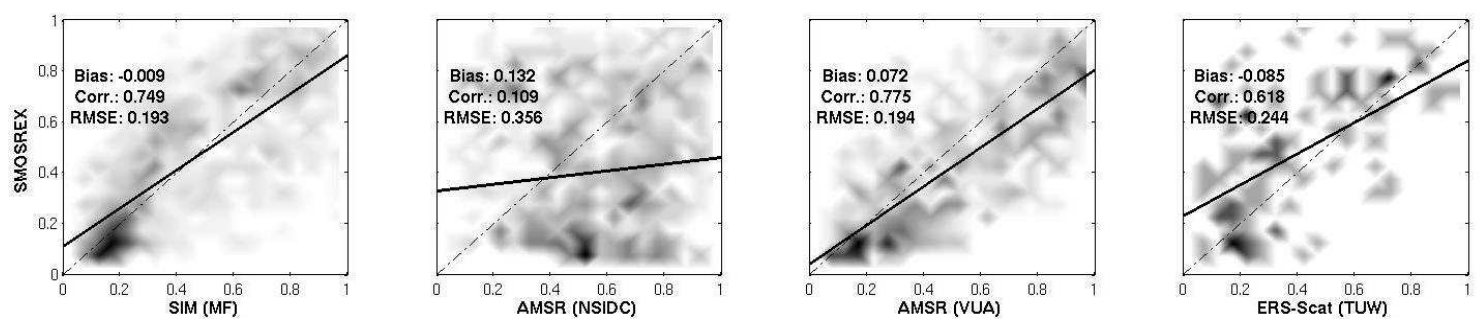
Fig. 3 Maps of the coefficient of correlation between the various soil moisture products (normalised values) over mainland France. The circles highlight the 6 major metropolitan areas of France.

\section{Soil Moisture (Normalised) Correlation Maps for France, Years 2003-2005}
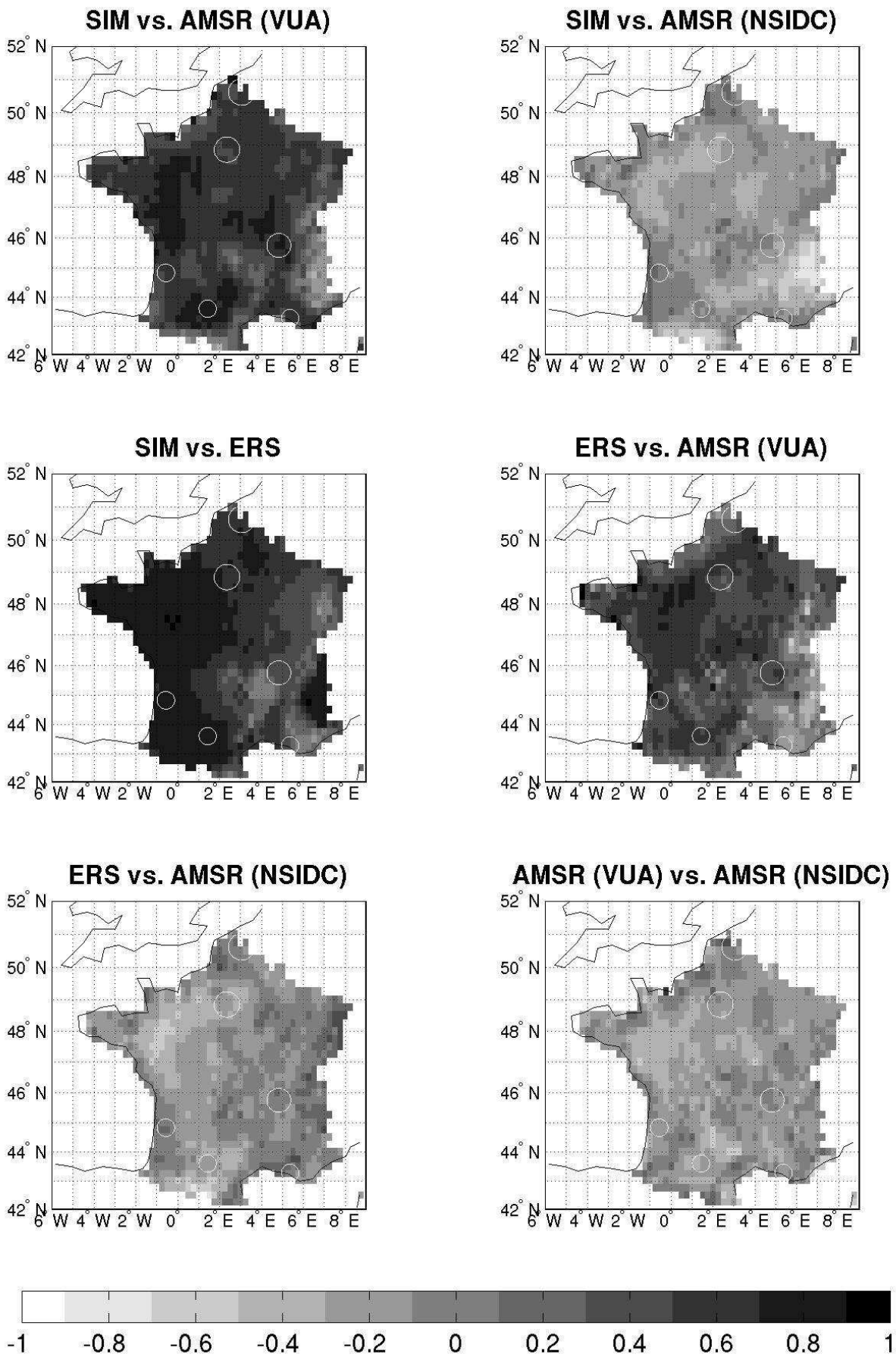
Fig. 4 Location of pixels with the different dominant land cover types (cultivated soils, grasslands, and forests), based on the fractional covers obtained from Ecoclimap and aggregated to $0.25^{\circ}$ resolution.
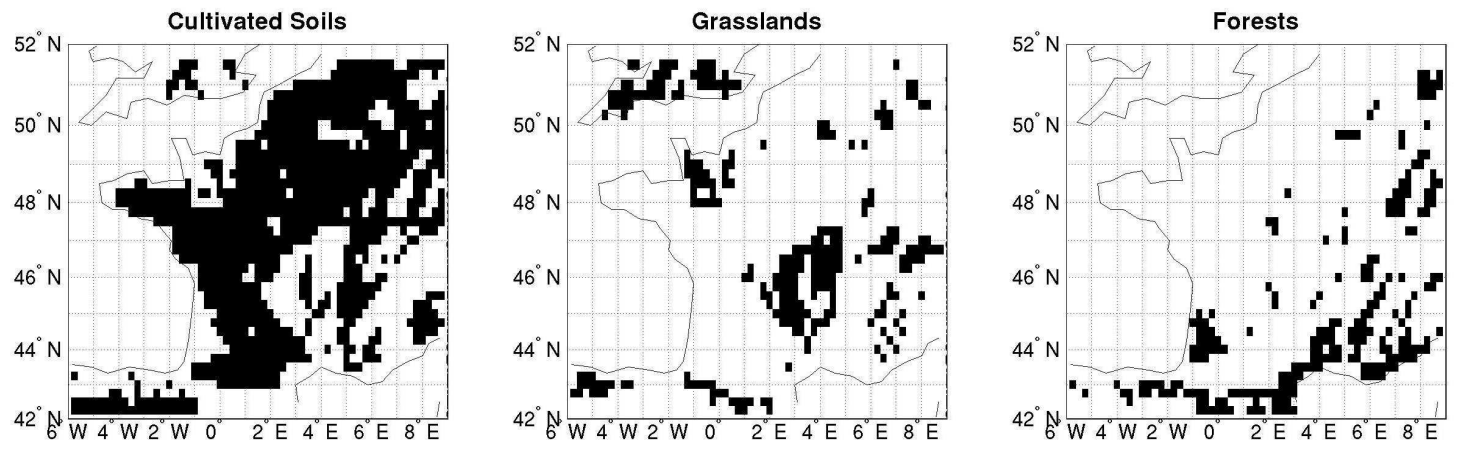
Fig. 5 Vegetation type specific comparison of the different soil moisture products for the three dominant vegetation types (a) cultivated soils, b) grasslands, c) forests), using the data from the period 2003-2005. The scatterplots and their corresponding statistics are located on opposite sides of each figure, ie. the scatterplot of the data pair SIM-AMSR (VUA) is in the top left hand corner, while the respective statistical values are found in the bottom right hand corner. Darker regions show a higher density of data points.

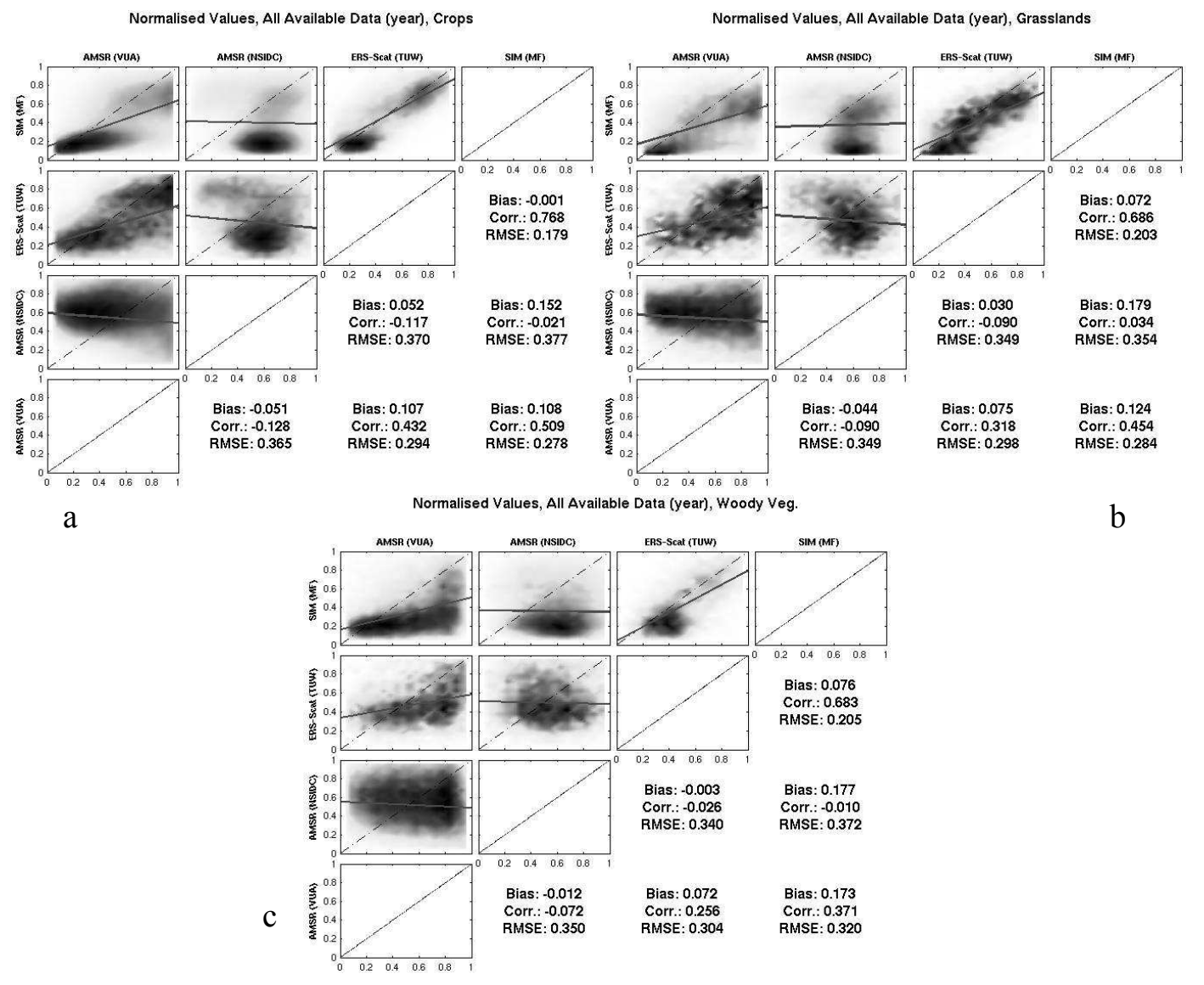


Fig 6. Histograms showing the relative frequency (vertical axis) of the various normalised soil moisture observations (horizontal axis) and predictions for the years 2003-2005 for the SMOSREX site: SIM model, AMSR-E product of VUA-NASA, AMSR-E product of NSIDC, ERS-Scat product of University of Vienna, in situ observations.
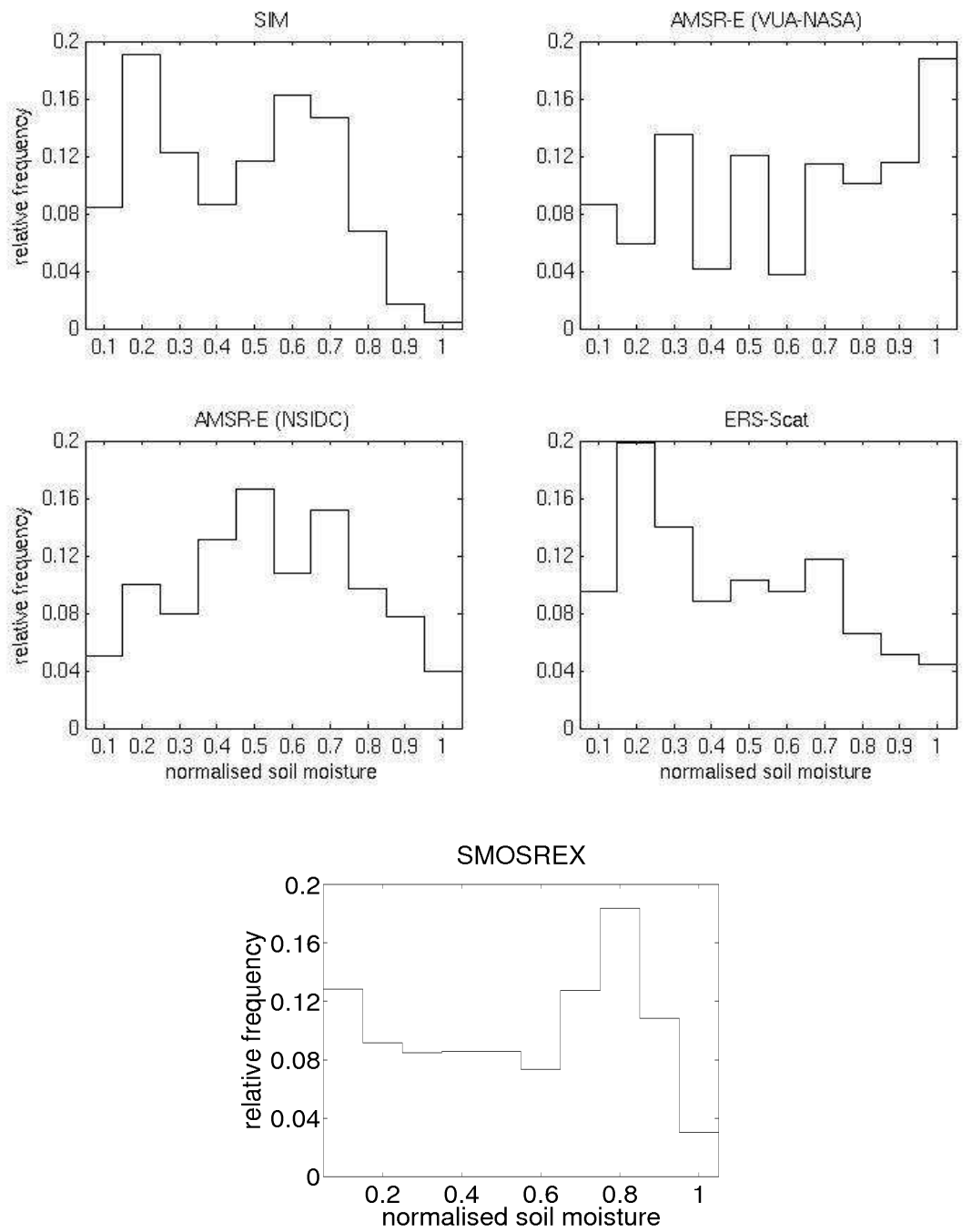
Fig 7. Histograms showing the relative frequency (vertical axis) of the various normalised soil moisture observations (horizontal axis) and predictions for the years 2003-2005 for whole of France: SIM model, AMSR-E product of VUA-NASA, AMSR-E product of NSIDC, ERSScat product of University of Vienna.
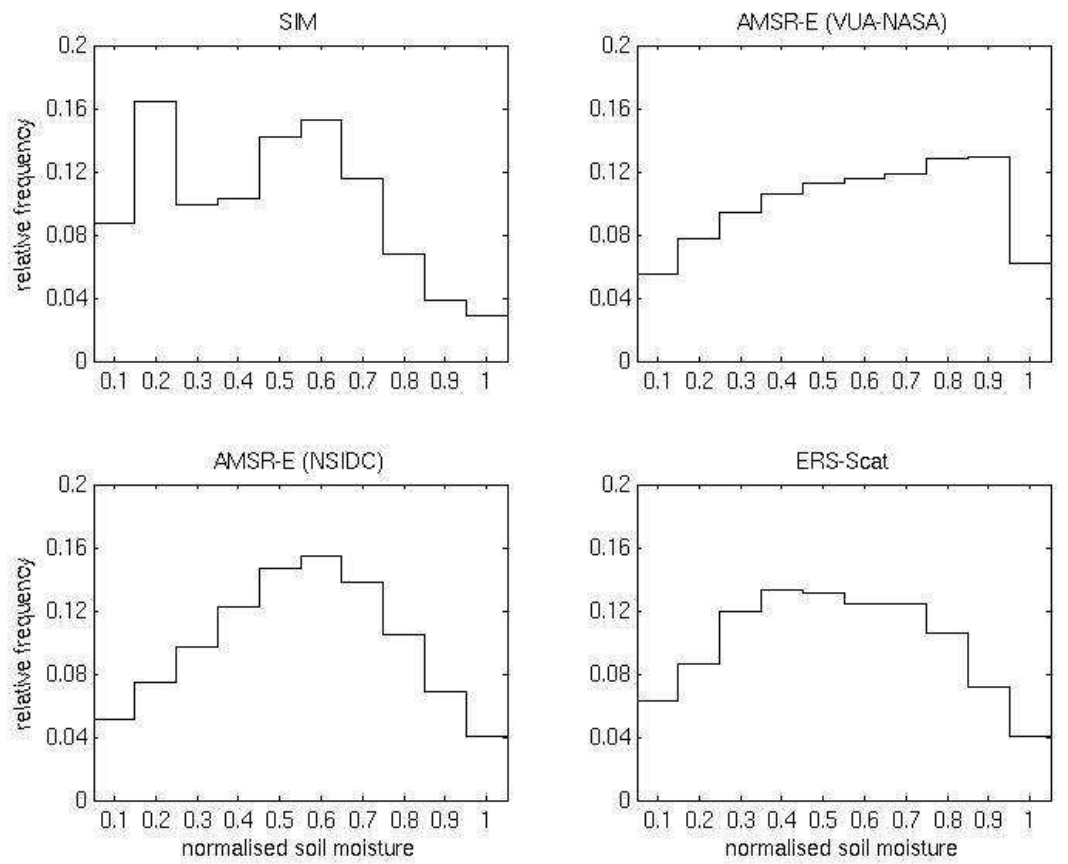
Fig. 8 Scatterplots showing the comparison of the various soil moisture products for pixels with herbaceous vegetation only (cultivated soils and grasslands) for the four seasons a) spring, b) summer, c) autumn, and d) winter. The scatterplots and their corresponding statistics are located on opposite sides of each figure, ie. the scatterplot of the data pair SIMAMSR (VUA) is in the top left hand corner, while the respective statistical values are found in the bottom right hand corner. Darker regions show a higher density of data points.

a

Normalised Values, All Available Data (spring), Herbaceous Veg.

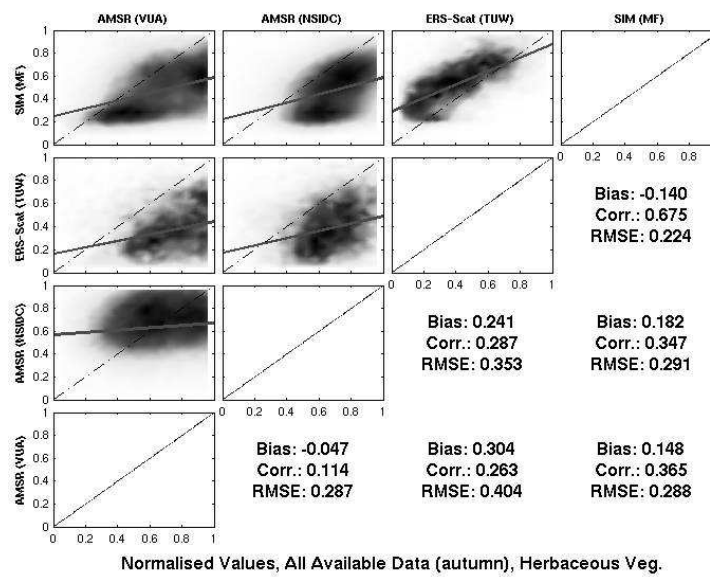

Normalised Values, All Available Data (autumn), Herbaceous Veg.

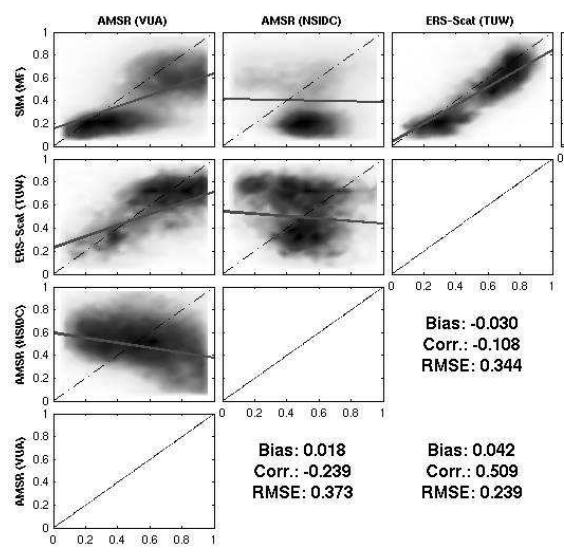

C

Bias: 0.059
Corr: 0.775 Corr.: 0.775

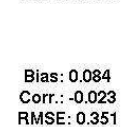

RMSE: 0.351

Bias: 0.111
Corr.: 0.479

Corr.: 0.479
RMSE: 0.274 b
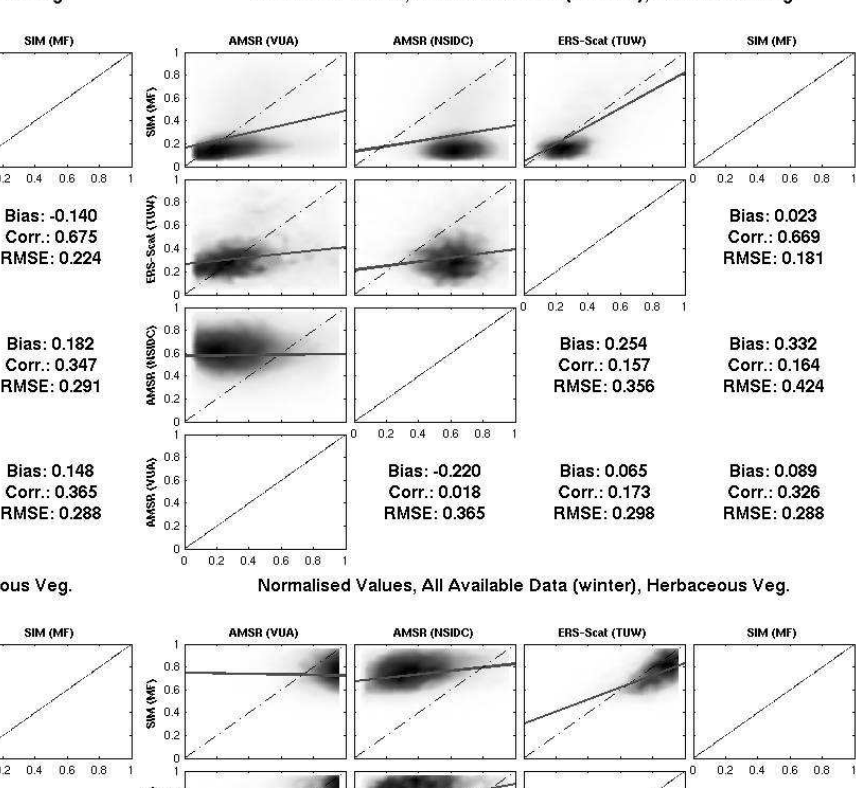

AMSR (NSIDC)
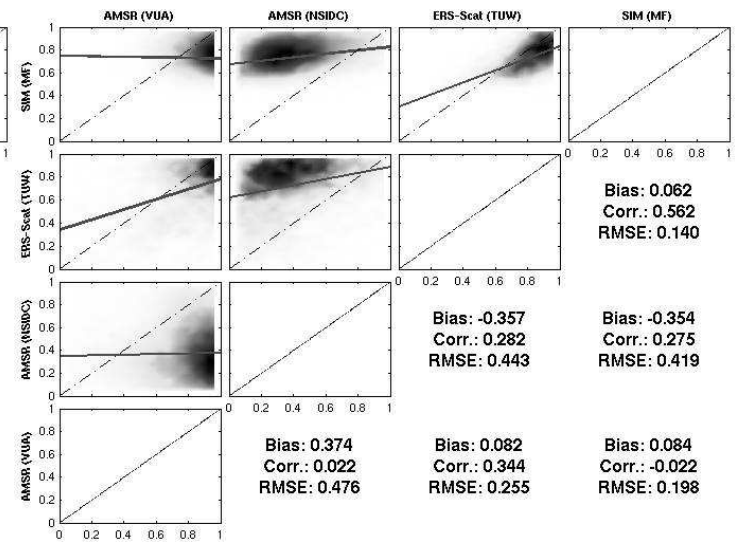

Bias: 0.062 Corr.: 0.562
RMSE: 0.140

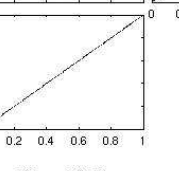

Bias: $0.374 \quad$ Bias: 0.082 Corr.: 0.022 Corr.: 0.344 RMSE: 0.255

Bias: 0.084 Corr.: -0.022 RMSE: 0.198 